\title{
Yetişkin hastada böbrek içeren Bochdalek hernisi
}

\section{Bochdalek hernia containing kidney in adult patient}

\author{
Fatih Erdem $^{1}$ \\ Gülen Demirpolat ${ }^{1}$ D \\ Fuat Erel ${ }^{2}$ \\ Erdoğan Bülbül ${ }^{1}$ \\ Emrah Akay ${ }^{1}$ \\ Bahar Yanık ${ }^{1}$ \\ ${ }^{1}$ Balıkesir Üniversitesi Tıp Fakültesi, Radyoloji Anabilim Dalı, Balıkesir, Türkiye \\ ${ }^{2}$ Balıkesir Üniversitesi Tıp Fakültesi, Göğüs Hastalıkları Anabilim Dalı, Balıkesir, Türkiye
}

Öz

Bochdalek hernisi konjenital diyafragmatik herniler arasında en sık görülen tiptir. Posterolateral diyafragmatik defektten abdominal organların intratorasik kaviteye herniye olması ile karakterizedir. Yenidoğanda sık olmasına rağmen yetişkinlerde nadir olarak görülür. Literatürde yaklaşık 100-150 yetişkin vaka raporlanmıştır. Bochdalek hernili hastalarda herni içeriği sıklıkla batın içi yağdan ibarettir. İntratorasik böbrek görülmesi son derece nadir bir durumdur. Biz bu olgu sunumunda 51 yaşındaki kadın hastayı nadir görülen bu durumlardan dolayı sunuyoruz.

Anahtar Sözcükler: Bochdalek hernisi, intratorasik böbrek, toraks çok kesitli bilgisayarlı tomografi, yetişkin.

\begin{abstract}
Bochdalek hernia is the most common type of congenital diaphragmatic hernias. It is characterized by herniation of abdominal organs into intrathoracic cavity through posterolateral diaphragmatic defect. Although it is frequently seen in newborns, it is also seen in adults (1). In literature approximately 100150 adult case were reported (1). In patients with Bochdalek hernia content of hernia includes intraabdominal fat. Presence of intrathoracic kidney is extremely rare condition (7). We present this case of 51-year-old female patient because of these rare conditions.
\end{abstract}

Keywords: Bochdalek hernia, intrathoracic kidney, thorax multi-slice computerized tomography, adult.

\section{Giriş}

Bochdalek hernisi embriyogenez esnasında diyaframın posteriorunda füzyonun olmamasına bağlı gelişir (1). Yenidoğanda insidansı 1/2200 ile $1 / 12500$ arasında bildirilmiştir (2). Diyafragmatik defektin sol tarafta daha sık olduğu söylenmekle birlikte en azından yetişkinlerde bu konu tartışmalıdır (3). Herni içeriği sıklıkla yağdan ibarettir. Daha nadiren karaciğer, dalak, pankreas, barsak, adrenal bez ve böbrek de bu defekten intratorasik alana herniye olur $(1,4)$. Biz bu yazıda intraabdominal yağ ile birlikte sol böbrek üst polünün de intratorasik alana doğru uzandığı Bochdalek hernisi olgusunu literatür bilgileri dahilinde sunuyoruz.

Yazışma Adresi: Fatih Erdem

Balıkesir Üniversitesi Tıp Fakültesi, Radyoloji Anabilim Dalı,

Balıkesir, Türkiye

E-mail: mdftiherdem@gmail.com

Makalenin Geliş Tarihi: 05.11.2018

\section{Olgu Sunumu}

15 yıldır alerjik astım öyküsü olan, son dönemlerde artan öksürük, ses kısıklığı, hırıltı ve balgam çıkarmakta zorluk şikayeti ile hastanemizin göğüs hastalıkları polikliniğine başvuran 51 yaşındaki kadın hasta, iki yönlü akciğer grafisinde kalbin arkasında kuşkulu yumuşak doku opasitesi görülmesi nedeniyle, malignite ve pnömoni ayırıcı tanısı için kliniğimize yönlendirildi. Hastanın çok kesitli bilgisayarlı tomografisinde (ÇKBT), sol hemidiyaframın posteriorunda defekt izlendi; abdominal yağın ve sol böbreğin bu defektten toraks boşluğuna doğru herniye olduğu görüldü. Olgu yağ dokusu ve sol böbreğin üst polünü içeren Bochdalek hernisi olarak değerlendirildi (Şekil-1). 
ÇKBT'de akciğer parankim alanları değerlendirildiğinde peribronşial kalınlaşmalar ve periferik bronşiollerde mukus tıkaçları ile sağ akciğerde orta lobda; solda alt lob anteromedial ve posterior bazal segmentlerde atelektaziler izlendi. Bu bulgular astım ile uyumlu olarak değerlendirildi. Hastanın semptomlarının da mevcut astımı ile ilişkili olduğu düşünüldü ve Bochdalek hernisi için cerrahi tedaviye gerek görülmedi.

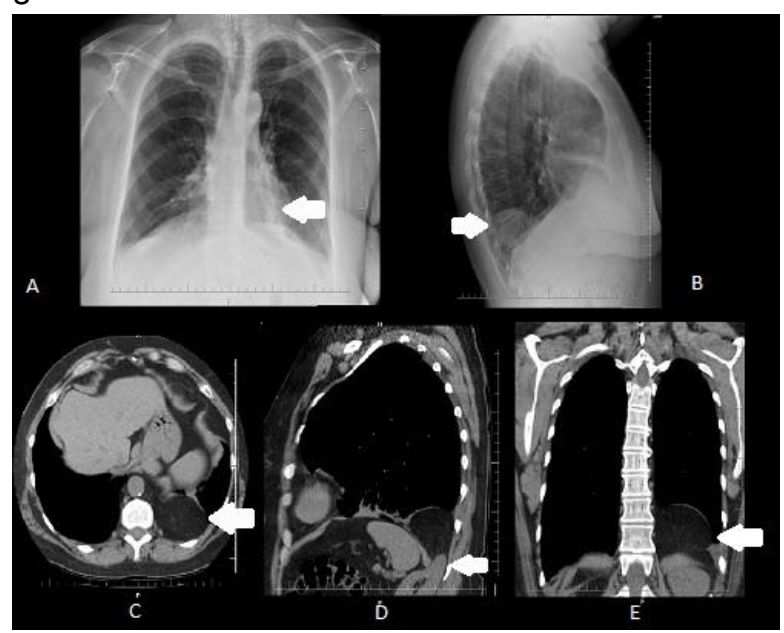

Şekil-1. A, B: İki yönlü akciğer grafisinde kalbin arkasında izlenen anormal yumuşak doku opasitesi (oklar).

C: Aksiyel BT kesitinde sol hemidiyaframın posteriorundaki defektten omentumun supradiyafragmatik alana doğru uzanımı izlenmektedir (ok).

D: Sagital reformat BT kesitinde sol hemidiyaframın posteriorundaki defektten omentumun ve sol böbreğin üst polünün supradiyafragmatik alana doğru uzanımı izlenmektedir (ok).

E: Koronal reformat BT kesitinde sol hemidiyaframın posteriorundaki defektten omentumun supradiyafragmatik alana doğru uzanımı izlenmektedir (ok).

\section{Tartışma}

Bochdalek hernisi genelde hayatın ilk birkaç haftasında solunum sıkıntısı ile ortaya çıkarken yetişkin olguların çoğu asemptomatiktir ve rastlantısal olarak saptanır. Semptomatik yetişkin hastaların klinik tanısı kolay değildir. Bu olgularda sıklıkla karın ağrısı, yemek sonrasında şişkinlik ve kusma gibi gastrointestinal sistemi işaret eden bulgular görülür. Öksürük, göğüs ağrısı ve nefes darlığı gibi pulmoner hastalık bulguları daha nadirdir. $(1,2,5,6)$.

Bochdalek hernisi lateral akciğer grafisinde posterior bazalde iyi sınırlı yumuşak doku opasitesi şeklinde izlenir. Akciğer grafisinde lingular kollaps, perikardiyal yağ yastığı, mediastinal lezyonlar, konsolidasyon, sekestrasyon, diyafragmanın kistik ve solid lezyonları da benzer görüntülere yol açabilir (6). Radyografinin duyarlıığı düşük olduğu için Bochdalek hernisinin bu lezyonlardan ayrımı güçtür. BT ile grafide izlenen yumuşak doku opasitesinin kaynaklandığı yer belirlenebilir. Ayrıca solid, kist, yağ dokusu ayrımı yapılabilir. Oluşturulan üç boyutlu görüntüler ile diyaframdaki fokal defektin yeri, büyüklüğü ve herninin içeriği detaylı şekilde değerlendirilebilir.

Bochdalek hernisinin toraksın hangi tarafında daha sık olduğu konusu tartışmalıdır.

Yetişkin hastalarda konvansiyonel abdomen BT raporlarının retrospektif tarandığı bir çalışmada rastlantısal Bochdalek hernisinin sıklığı $(\% 0,17)$ bulunmuştur. Aynı çalışmada beklenilenin aksine olguların büyük bölümünün (\%68) sağ taraflı olduğu görülmüştür. Olguların \%73'ünde herni içinde intraabdominal yağ veya sadece omentum saptanırken sağ veya sol tarafı herni ayrımı yapılmadan değerlendirildiğinde en sık saptanan organın (\%50) böbrek olduğu bildirilmiştir (4). Daha yakın zamanda yapılan ve ÇKBT görüntülerinin değerlendirildiği başka bir çalışmada ise insidental Bochdalek hernisinin prevalansı \%10,5 bulunmuş ve önceki çalışmalardan çok daha yüksek oranlarda olduğu gösterilmiştir. Bahsedilen çalışmada olguların $\% 37,4$ 'ünde herninin sağ tarafta, $\% 42,2$ 'inde sol tarafta, \%29'unda ise bilateral olduğu ayrıca olguların \% 1,41'inde herni içinde böbrek bulunduğu bildirilmiştir (7).

Toraks ÇKBT'lerin değerlendirildiği başka bir çalışmada insidental Bochdalek hernisinde böbreğin görülme insidansı $\% 5,5$ olarak bildirilmiştir (8).

Semptomatik Bochdalek hernili olgularda herni içeriği batına indirildikten sonra diyafragmatik defektin tamiri yapılır. Laparatomi en sık kullanılan yöntem olmakla birlikte; komplikasyon oranı düşük, hastanede kalış süresi kısa olduğu için tedavide laparoskopik yöntem de seçilebilir (2). Bochdalec hernisi ile birlikte olan intratorasik böbrek diğer intratorasik renal ektopilerden farklı olarak daha mobil olduğundan batına yerleştirilmesi daha kolaydır (5).

Sonuç olarak; Bochdalek hernisi nadiren intratorasik böbreğe yol açabilir. Yetişkin 
olgularda bu durum rastlantısal olarak açan olası diğer lezyonlardan ayırt edilmesi ve saptanabilir. Lateral akciğer grafisinde akciğerin içeriğinin belirlenmesi için ÇKBT inceleme tercih bazalinde, posteriorda yumuşak doku opasitesi edilir.

şeklinde izlenen herninin opasite artışına yol

\section{Kaynaklar}

1. Hamid KS, Rai SS, Rodriguez JA. Symptomatic Bochdalek hernia in an adult. JSLS 2010; 14 (2): 279-81.

2. Yagmur $\mathrm{Y}$, Yigit E, Babur M, Gumus $S$. Bochdalek hernia: a rare case report of adult age. Annals of Medicine and Surgery 2016; 5: 72-5.

3. Laaksonen E, Silvasti S, Hakala T. Right-sided Bochdalek hernia in an adult: a case report. Journal of Medical Case Reports 2009; 3: 9291.

4. Mullins ME, Stein J, Saini SS, Mueller PR. Prevalence of incidental Bochdalek's hernia in a large adult population. AJR 2001; 177: 363-6.

5. Ülkü R, Avcı A, Onat $S$, Özçelik C. Bir yetişkinde sağ taraf Bochdalek hernisi: Olgu sunumu. Türk Göğüs Kalp Damar Cer Derg 2011; 19 (1): 104-6.

6. Meteroğlu F, Şahin A, Oruç M, Onat S. Yetişkin Bochdalek hernisi: Sekiz hastanın analizi. Türk Göğüs Kalp Damar Cer Derg 2015; 23 (3): 514-8.

7. Temizöz O, Gençhellaç H, Yekeler E et al. Prevalence and MDCT characteristics of asymptomatic Bochdalek hernia in adult population. Diagn Interv Radiol 2010; 16 (1): 52-5.

8. Kinoshita F, Ishiyama M, Honda S, Matsuzako M, Oikado K, Kinoshita T, Saida Y. Late-presenting posterior transdiaphragmatic (Bochdalek) hernia in adults prevalence and MDCT characteristics. J Thorac Imaging. 2009; 24 (1): 17-22. 